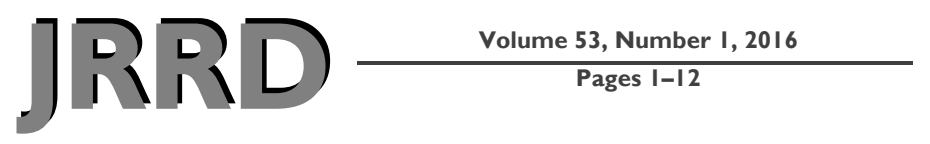

\title{
Pain research using Veterans Health Administration electronic and administrative data sources
}

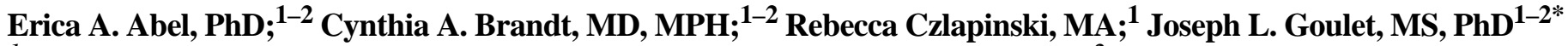 \\ ${ }^{1}$ Department of Veterans Affairs Connecticut Healthcare System, West Haven, CT; ${ }^{2}$ Yale School of Medicine, New \\ Haven, $C T$
}

\begin{abstract}
Health services researchers are using Veterans Health Administration (VHA) electronic health record (EHR) data sources to examine the prevalence, treatment, and outcomes of pain among Veterans in VHA care. Little guidance currently exists on using these data; thus, findings may vary depending on the methods, data sources, and definitions used. We sought to identify current practices in order to provide guidance to future pain researchers. We conducted an anonymous survey of VHA-affiliated researchers participating in a monthly national pain research teleconference. Thirty-two researchers (89\%) responded: $75 \%$ conducted pain-focused research, 78\% used pain intensity numeric rating screening scale (NRS) scores to identify pain, $41 \%$ used International Classification of Diseases-9th Revision codes, and 57\% distinguished between chronic and acute pain using either NRS scores or pharmacy data. The NRS and pharmacy data were rated as the most valid pain data sources. Of respondents, $48 \%$ reported the EHR data sources were adequate for pain research, while $45 \%$ had published peer-reviewed articles based on the data. Despite limitations, VHA researchers are increasingly using EHR data for pain research, and several common methods were identified. More information on the performance characteristics of these data sources and definitions is needed.
\end{abstract}

Key words: administrative data, computerized medical records, data collection, data interpretation, data mining, electronic health records, information storage and retrieval, pain, pain management, Veterans.

\section{INTRODUCTION}

The Veterans Health Administration (VHA) uses an electronic health record (EHR) to collect clinical and administrative data. Because the VHA is a national

Abbreviations: CAHPS = Consumer Assessment of Healthcare Providers and Systems, CDW = Corporate Data Warehouse, CPRS = Computerized Patient Record System, EHR = electronic health record, HAIG = Health Analysis and Information Group, HERC = Health Economics Resource Center, HSR\&D = Health Services Research and Development Service, ICD-9 = International Classification of Diseases-9th Revision, MCA = Managerial Cost Accounting, MedSAS = Medical SAS, NEPEC = Northeast Program Evaluation Center, NPCD = National Patient Care Database, NRS = pain intensity numeric rating screening scale, OIF/OEF = Operation Iraqi Freedom/ Operation Enduring Freedom, PRWG = Pain Research Working Group, PTF = Patient Treatment File, PTSD = posttraumatic stress disorder, RAI/MDS = Resident Assessment Instrument/ Minimum Data Set, SHEP = Survey of Healthcare Experiences of Patients, VA = Department of Veterans Affairs, VHA = Veterans Health Administration, VIReC $=$ VA Information Resource Center, VistA = Veterans Health Information Systems and Technology Architecture.

*Address all correspondence to Joseph L. Goulet, MS, PhD; Pain Research Informatics Multi-morbidities and Education Center (PRIME), VA Connecticut Healthcare System, Bldg 35a, Rm 2-207, 950 Campbell Ave, West Haven, CT 06516; 203-932-5711, ext 5325; fax: 203-9374926. Email: joseph.goulet@va.gov http://dx.doi.org/10.1682/JRRD.2014.10.0246 
integrated healthcare system that serves a diverse population of over 8 million Veterans per year in more than 140 facilities [1], EHR-based data can potentially provide valuable information on a variety of healthcare-related issues.

Researchers have successfully used EHR and administrative data in different ways. Such data have been used to create condition-specific registries [2], conduct data quality evaluations [3], differentiate the severity of mental health and medical conditions [4], describe longitudinal health services utilization [5], study outcomes [6], and improve the quality of care [7]. Within VHA, researchers have used EHR and administrative data to examine a diverse array of issues [8] such as mental health [9-11], human immunodeficiency virus [12-13], women's Veterans health [14], sex differences [15-16], diabetes [17-18], and stroke [19-20].

Pain is one of the most common reasons for seeking medical care [21], and health services researchers are using VHA EHR data sources to examine the prevalence, treatment, effect, and pain management practices among Veterans in VHA care. For example, Sinnott et al. evaluated several methods for identifying individuals with neck and back pain [22]. They identified seven unique published algorithms and outlined the similarities and differences in the structure and definitions of the algorithms. They then assessed and compared the algorithms by applying them to VHA administrative data (e.g., Patient Treatment Files [PTFs] for inpatient data and the National Patient Care Database [NPCD] for outpatient data). Lisi et al. compared VHA administrative data and structured chart review and identified and tested methods to distinguish between acute and chronic nonacute lower back pain among Veterans [4]. Models they constructed included several variables in addition to International Classification of Diseases-9th Revision (ICD-9) codes (e.g., prescriptions, consultations, and imaging orders). Variables were extracted from several Veterans Health Information System and Technology Architecture (VistA) databases and files (VistA stores EHR data).

Haskell et al. evaluated sex differences in the prevalence of overall pain, moderate to severe pain, persistent pain, and pain assessment in a cohort of Operation Iraqi Freedom/Operation Enduring Freedom (OIF/OEF) Veterans seen at an outpatient VHA clinic in the first year after their last deployment [15]. The researchers obtained demographic and military service information from the OIF/ OEF roster, a database of Veterans who have separated from military service and have enrolled in VHA healthcare. The source of the roster is the Defense Manpower Data Center [23]. Visit information, ICD-9 codes, and pain intensity numeric rating screening scale (NRS) scores were obtained from the Corporate Data Warehouse (CDW).

Goulet et al. examined the degree of agreement between EHR-based and patient survey-based NRS scores and examined factors that could explain discrepancies [24]. Finley et al. studied the association of the polytrauma clinical triad (the co-occurrence of posttraumatic stress disorder [PTSD], traumatic brain injury, and chronic pain) with suicide-related behavior risk among OIF/OEF Veterans [8]. They identified Veterans using the OIF/OEF roster and used administrative data (e.g., VHA inpatient and outpatient data) to identify baseline characteristics (e.g., ICD9 codes) and outcomes (e.g., suicide ideation, attempted or self-inflicted injury) [8]. Using a cohort of OIF/OEF Veterans, Seal et al. investigated the association of mental health disorders, in particular PTSD, on patterns of opioid prescription use and adverse clinical outcomes such as overdose and accidents [25]. VHA data sources used included the OIF/OEF roster, clinical visit and diagnostic information, and pharmacy records.

These studies highlight the variety of methods, definitions, and data sources used in pain-related research. While there are different approaches to using VHA EHR and administrative data, factors such as the inherent structure of VHA data (i.e., the large number of available data sources and data elements) and the existence of different relevant data owners and procedures to gain access to data sources can affect research results. Thus, research findings can vary depending on the methods and sources of data that researchers use to identify samples of patients and to define outcomes. For example, some may approach the identification of patients with pain through pharmacy dispenses of opioid medications, by NRS scores of a certain threshold (e.g., $\geq 4$ to indicate moderate to severe pain), by ICD-9 code, or through a combination thereof. Different definitions can contribute to pain researchers arriving at very different conclusions.

The use of EHR data, originally collected for clinical and administrative purposes and not research purposes, highlights the importance of establishing how best to use the available data to conduct pain-related research. As a first step toward establishing best practices to leverage optimal use of VHA EHR data, we conducted an anonymous survey of VHA-affiliated pain researchers. The survey results were intended to serve as a basis for future 
efforts to derive a consensus about recommended data sources, definitions, and methods to aid researchers in conducting studies that are comparable and consistent and ultimately to help improve healthcare services for Veterans.

The survey asked about respondents' research focuses, how they defined certain concepts (e.g., pain, acute and chronic pain), and whether they used a comparison or control group in their most recent research. We asked which specific national data sources they used in their pain research, which sources they used to identify the presence of pain, and how valid they felt the sources were. We inquired about potential barriers to data use, whether VHA data were adequate for pain research, and whether the respondents would be willing to participate in an expert panel to discuss issues and recommendations for pain research using VHA data.

\section{METHODS}

\section{Participants}

In 2012, all active members $(n=36)$ of the national VHA Pain Research Working Group (PRWG) were invited to participate in a voluntary, one-time, online survey about their use of VHA EHR and administrative data in pain-related research. The PRWG was created to support a key objective of the VHA National Pain Management Strategy: "Identifying research opportunities and priorities in pain management and facilitating collaborative research efforts" [26]. Members of the group include VHA investigators as well as collaborating investigators outside of the VHA. The Department of Veterans Affairs (VA) Connecticut Healthcare System Human Subjects Subcommittee approved this investigation.

The study principal investigator (J.G.) sent an email announcement to the group using a preexisting email distribution list as a source for names. Email messages were sent once a month for 3 mo (totaling three emails) to all group members, inviting respondents' voluntary and anonymous participation in an online survey. Respondents used REDCap (Research Electronic Data Capture) [27], a secure, Web-based application designed to support data capture for research studies, to complete the survey. No names or personally identifying information about either respondents or VHA patients were collected. Rather, the survey asked about primary affiliation, professional discipline, primary service department, pain research focus, and use and opinions of VHA EHR and administrative data.

\section{Survey Questions}

See the Appendix (available online only) for the survey questions used in this study.

\section{Data Source Use and Validity}

We asked survey respondents to indicate whether they used any of eight EHR and administrative data sources that have been used in other areas of research and to rate their opinion of the validity of the source on a scale of 1 (not valid) to 7 (valid).

\section{Most Recent Research}

We asked seven questions about respondents' most recent research, including several dichotomous "yes/no" questions, such as whether they distinguished between chronic and acute pain, used a comparison or control group, or examined recurrence of pain. We then asked open-ended questions about how they defined pain and chronic pain and asked them to identify the geographic area (e.g., national or local VHA facility only) of their most recent research. Finally, we asked whether respondents had ever published any pain-focused peer-reviewed articles.

\section{Barriers to Data Source Use}

We asked respondents about barriers to their use of VHA electronic and administrative data. We provided a list of 10 known barriers (plus an option for "none”). We compiled the list of barriers based on the combined experience of authors (J.G., C.B.) who have developed three large VHA data cohorts. Respondents could also add any additional barriers not listed. We also asked them to rate each barrier, including ones the respondents added, as a "minor barrier," “major barrier," or "not a barrier."

\section{Adequacy of Data for Pain Research}

Survey respondents were asked the following question to ascertain their opinion of the adequacy of data sources for pain research: "Do you think VHA electronic and administrative data are adequate for pain research?” Single questions were then asked to elicit feedback about (1) how respondents would improve VHA electronic and administrative data for pain research and (2) whether respondents would be interested in participating in an expert panel to discuss issues in pain research using VHA data. 


\section{Data Sources and Definitions}

There are approximately 139 data sources within VHA [28]. Given this sizeable number of data sources potentially available to conduct pain research, we felt it would be useful to identify and ask respondents about a subset of those sources often used in pain research. We relied on our prior experience conducting pain research and the prior publications of VHA pain-related researchers to identify the subset and describe them here for clarity and informational purposes. Hynes provides information about many of these resources and gaining access to them [28].

\section{Corporate Data Warehouse}

The CDW is a national repository of VHA clinical and administrative data [29]. Data include national clinical, enrollment, financial, administrative, utilization, and benefits information consolidated from multiple VHA data sources. The CDW allows for a standardized database structure and facilitates analysis and reporting.

\section{Veterans Health Administration Medical SAS Inpatient and Outpatient Data Sets}

The Medical SAS (MedSAS) inpatient and outpatient data sets consist of national VHA healthcare encounter data, specifically workload information at the encounter, visit, or stay level, for inpatient and outpatient healthcare encounters. MedSAS inpatient data are obtained from the PTF and both the outpatient and inpatient encounter MedSAS data are taken from the NPCD [30]. The NPCD is a centralized database of integrated patient care data from VistA.

\section{Department of Veterans Affairs Managerial Cost Accounting System}

The Managerial Cost Accounting (MCA) system (formerly known as the Decision Support System) is a cost allocation system that can generate the costs of healthcare use for hospital stays and outpatient care at an individual patient level. Examples of data reported include costs of ordering chest X-rays, clinic visits, and inpatient visits [31].

\section{Beneficiary Identification and Records Locator System Death File}

The Beneficiary Identification and Records Locator System death file is a Veterans Benefits Administrationextracted death file database that contains cumulative information about Veterans' deaths. This database is compiled from multiple sources such as VHA hospitals, family members applying for benefits, the VA National Cemetery Administration, and the Social Security Administration.

\section{National Surgical Quality Improvement Program}

The National Surgical Quality Improvement Program includes risk-adjusted data extracted from patient charts and provides preoperative to postoperative patient outcomes.

\section{Pharmacy Benefits Management}

Pharmacy Benefits Management is a comprehensive national database containing information about all prescriptions dispensed at a VHA pharmacy or consolidated mail outpatient pharmacy since fiscal year 1999. Data include "medication dispensing utilization information for prescription fills in VHA pharmacies" [32], dosing instructions, National Drug Code identifiers, cost, and provider information.

\section{Survey of Healthcare Experiences of Patients}

The Survey of Healthcare Experiences of Patients (SHEP) is a VHA survey program that assesses patient experiences with inpatient and outpatient healthcare with the overall goal of improving the quality of VHA healthcare. In 2010, the SHEP program began using the Agency for Healthcare Research and Quality's Consumer Assessment of Healthcare Providers and Systems (CAHPS) family of survey instruments. As developed, these surveys are standardized and thus comparable across settings, and their psychometric properties are well-documented [33]. The SHEP program implements additional CAHPS survey instruments in accordance with VHA priorities.

\section{Health Analysis and Information Group Pain Management Survey Data}

The Health Analysis and Information Group (HAIG) pain management survey data include a comprehensive field-based survey of pain management in all VHA facilities conducted in 2009 by the HAIG in collaboration with the Pain Management Program Office. All facilities responded, and the role of respondents varied by facility (e.g., pain management point of contact or not). Available data include adherence to VHA pain management directive, clinical care characteristics, pain management 
stepped care model implementation, and focused review of specific priority areas.

\section{Bar Code Medication Administration}

The Bar Code Medication Administration is a VistA module that provides inpatient medication dispensing safety and control to reduce inpatient medication errors. It does so by electronically validating and documenting medications for patients. The system visually alerts clinicians when medication-dispensing conditions are not met.

\section{Department of Veterans Affairs Resource Centers}

We included in the survey four of the eight national VA resource centers that are commonly used by VHA pain researchers. We selected these four sources by drawing on our experience as pain researchers.

\section{Serious Mental Illness Treatment Resource and Evaluation Center}

The Serious Mental Illness Treatment Resource and Evaluation Center is a VA Health Services Research and Development Service (HSR\&D) research center that develops and maintains two national data repositories: the National Psychosis Registry and the National Registry for Depression [34].

\section{Health Economics Resource Center}

The Health Economics Resource Center (HERC) is an HSR\&D resource center that provides data about VHA facility, departmental, and individual healthcare costs, specifically inpatient and outpatient costs along with fee basis or costs related to outside care with a provider contracted with VHA. HERC also produces several resources, including MCA cost data [35].

\section{Department of Veterans Affairs Information Resource Center}

The VA Information Resource Center (VIReC) is an HSR\&D resource center that develops and disseminates knowledge about data resources and provides guidance and assistance to researchers [31]. VIReC also provides access to VA and Centers for Medicare and Medicaid Services data, including United States Renal Data System data.

\section{Northeast Program Evaluation Center}

The Northeast Program Evaluation Center (NEPEC) is the evaluation division of the National Center for
PTSD [36]. NEPEC is responsible for evaluating Office of Mental Health services programs, including PTSD clinical programs.

\section{RESULTS}

Of 36 researchers contacted, 32 (89\%) respondents completed the survey. Nearly all (94\%) identified their primary affiliation as VHA. Respondents included psychologists (33\%), physicians (25\%), epidemiologists (13\%), and statisticians (13\%). Seventy-two percent reported conducting research in an outpatient setting, and 44 percent identified chronic pain as their primary area of research. The majority of respondents (75\%) had been a principal investigator or coinvestigator on pain-focused studies. Two-thirds (67\%) reported they had received VHA funding for their most recent pain-related research, 25 percent reported they had received funding from "other" sources, and 8 percent reported they had received National Institutes of Health funding. No respondents reported Department of Defense funding.

As shown in Table 1, more respondents endorsed using NRS scores (78\%), ICD-9 codes for pain (66\%), and/or Computerized Patient Record System (CPRS) progress notes (41\%) to identify the presence of pain than other data sources. Respondents' impressions of the validity of the sources of pain data were highest for

Table 1.

Sources of pain data.

\begin{tabular}{lcc}
\hline \multicolumn{1}{c}{ Source } & Percent & $\begin{array}{c}\text { Impression of Data } \\
\text { Validity } \\
\text { (median score) }\end{array}$ \\
\hline NRS Scores & 78 & 5 \\
ICD-9 Codes for Pain & 66 & 4 \\
CPRS Progress Notes & 41 & 4 \\
Pharmacy & 39 & 5 \\
CPT Codes & 38 & 4 \\
CPRS Problem List & 38 & 3.5 \\
Other (e.g., patient self-report, & 24 & 5.5 \\
$\quad$ RAI/MDS) & 22 & 4 \\
Clinic Stop Codes & 16 & 4 \\
CPRS Discharge Summary & \multicolumn{2}{|c}{} \\
${ }^{*}$ Individuals could endorse multiple sources and thus numbers do not sum to \\
100\%. \\
${ }^{\dagger}$ Range = 1 (not valid) to 7 (valid). \\
CPRS = Computerized Patient Record System, CPT = Current Procedural \\
Terminology, ICD-9 = International Classification of Diseases-9th Revision, \\
NRS = pain intensity numeric rating screening scale, RAI/MDS = Resident \\
Assessment Instrument/Minimum Data Set. \\
\hline \hline
\end{tabular}


“other” (including patient self-report and the Resident Assessment Instrument/Minimum Data Set [RAI/MDS]), NRS scores, and pharmacy sources.

In their most recent research, 41 percent of respondents reported they relied on ICD-9 codes only and 21 percent of respondents used NRS scores only to define pain. More than half of the respondents (57\%) distinguished between chronic and acute pain.

Among those who reported how they defined chronic pain, most reported using NRS scores of $\geq 4$ during some interval of time. Nearly one-third of the respondents (32\%) constructed a comparison or control group, 25 percent had a national focus, 13 percent had a Veterans Integrated Service Network focus, and 16 percent had a local facility focus. Less than half (45\%) reported they published pain-focused peer-review articles using VHA electronic and administrative data.

We ascertained respondents' perceived barriers to the use of VHA electronic and administrative data for painrelated research. As shown in Table 2, "insufficient level of detail in data" received the greatest percentage of endorsements as a major barrier (33\%). The other identified major barriers included "data management issues (e.g. cleaning data)" and "data quality (e.g. completeness, lack of validation)" (both 27\%) and "privacy/Health Insurance Portability and Accountability Act concerns" (23\%). Two factors received the greatest percentage of endorsements as "not a barrier": "timeliness of data" (77\%) and "lack of hardware to house data (e.g., computer storage)” (73\%).

Regarding use of VHA data sources, as shown in Table 3, less than half (44\%) of the respondents reported using the VHA's integrated data warehouse (CDW) or the
MedSAS data sets (47\%). Of note, despite the evident use of VHA data sources by these researchers, only 48 percent thought that the data sources were adequate for pain research. More than half of respondents (58\%) said they would be willing to participate in an expert panel to discuss issues in pain research using VHA data.

\section{DISCUSSION}

The results of this survey provide insight into how VHA pain researchers use VHA EHR and administrative data to conduct pain-related research. Nearly half of the respondents did not think VHA EHR and administrative data were adequate for pain research. Despite limitations in these data sources, pain researchers are using them and in different ways. The survey results also showed variations in key approaches to pain research, including which specific data sources were used, how chronic pain was defined, how chronic and acute pain were distinguished, whether a comparison or control group was used, and perceived barriers to using such data sources for pain research.

The majority of respondents endorsed using the NRS scores and/or ICD-9 codes. The NRS is a brief instrument, is easy to administer, correlates with other pain intensity measures, and is widely used in large healthcare settings and research. Thus, NRS scores may be relatively easier to obtain from EHR and administrative data relative to other pain data. While this survey result is similar to published literature, there are issues with reliance on NRS scores. They do not describe important

Table 2.

Barriers to use of Veterans Health Administration electronic and administrative data for pain research.

\begin{tabular}{lccc}
\hline \multicolumn{1}{c}{ Barrier } & Not a Barrier (\%) & Major Barrier (\%) & Minor Barrier (\%) \\
\hline Insufficient Level of Detail in Data & 7 & 33 & 60 \\
Data Management Issues (e.g., cleaning data) & 10 & 27 & 63 \\
Data Quality (e.g., completeness, lack of validation) & 13 & 27 & 23 \\
Privacy/HIPAA Concerns & 27 & 20 & 17 \\
Inability to Access Data & 17 & 10 & 7 \\
Lack of Expertise in Analyzing Data & 53 & 30 & 30 \\
Data Security & 50 & 77 & 3 \\
Timeliness of Data & 73 & 27 \\
Lack of Hardware to House Data (e.g., computer storage) & 23 \\
Lack of Standardization (e.g., site variation) & & 30 \\
Note: Individuals could endorse multiple resources and thus numbers do not sum to 100\%. & & 23 \\
HIPAA = Health Insurance Portability and Accountability Act. & & \\
\hline \hline
\end{tabular}


Table 3.

Top five Veterans Health Administration resources used in pain research.

\begin{tabular}{lc}
\hline \multicolumn{1}{c}{ Resource } & Percent \\
\hline Medical SAS Data sets & 47 \\
Corporate Data Warehouse & 44 \\
Decision Support System & 28 \\
Beneficiary Identification and & 22 \\
$\quad$ Records Locator System Death File & \\
Survey of Healthcare Experiences of Patients & 16 \\
\hline \hline
\end{tabular}

information (e.g., persistence of pain, level of impairment), and they may underestimate direct patient reports of pain [24].

ICD-9 codes are assigned to and available for most inpatient and outpatient encounters, are captured in EHR and administrative data, and thus are relatively easy to access. However, they are often used for purposes that are a departure from their original intent [37], and their accuracy in identifying patients with specific conditions is variable. Because of reliability and validity issues using ICD-9 codes to identify patients, including those with pain [38], researchers have developed identification algorithms to improve accuracy (e.g., using a specific number of inpatient and/or outpatient ICD-9 codes within a given time frame) [12,38]. Pain researchers have developed and evaluated identification algorithms that use ICD-9 codes (along with other data) to identify patients with pain $[4,6-7,22]$.

Our survey results suggest that VHA pain researchers use EHR and administrative data sources and recognize and capitalize on their advantages for research. VHA EHR and administrative data sources contain information on a large and diverse sample of individuals, and much of the data are entered or stored in structured fields. Researchers may be able to evaluate treatment outcomes using observational designs across a wider range of clinical settings, geographical regions, and patients and have access to samples of patients in preparation for recruitment for clinical trials [2] and/or survey studies. Use of EHR and administrative data for research may also be less expensive and time-consuming than studies that require patient recruitment and/or data collection [39]. In addition, use of existing data may reduce participant risk (e.g., reduce study intervention risk) and participant burden (e.g., eliminate the burden or expense of traveling to participate in a research study or time needed to complete a protocol). The variability in the methods, data sources, and definitions used by survey respondents may also reflect these advantages of EHR and administrative data, including the potential for greater flexibility in designing and executing research.

This survey highlights some of the known limitations to using EHR and administrative data for research. Because these sources are designed and implemented to support patient care and clinical processes, not research [40], the data needed to accomplish research objectives may not be available, may lack the information and details needed, or may be hard to retrieve. For example, EHR and administrative data omit valuable information [2], such as the severity of a patient's illness [30] and degree of disability. In addition, important information and details may be embedded in text format (e.g., clinician progress notes, secure email messages, and texts from patients) and thus are harder to retrieve and analyze than structured data.

Survey respondents appear to recognize these limitations as evidenced in their endorsement of both "insufficient level of detail in data" and "data quality (e.g., completeness, lack of validation)" as two major barriers to use of VHA EHR and administrative data. These limitations may also explain why survey respondents endorsed greater usage of NRS scores, ICD-9 codes, and CPRS progress notes to identify the presence of pain. Respondents may be less likely to use data they consider to have the highest validity (i.e., patient self-report and $\mathrm{RAI} / \mathrm{MDS}$ ), because this information is not available, is difficult to ascertain on a large scale (e.g., patient selfreport), or is available for a specific population such as patients in nursing homes (e.g., RAI/MDS) or a limited number of patients (e.g., study-specific surveys). Respondents appear to want more in-depth data about pain (such as the PEG instrument [41]) in VHA EHR and administrative data and may be using NRS scores, ICD-9 codes, and CPRS progress notes in the absence of more detailed and better data.

The lack of standardization over time of EHR and administrative data is another significant challenge. Specific databases may have been developed and implemented in response to distinct administrative, operational, quality improvement, or clinical needs and may be incompatible with national or organizational standards. The data rules, definitions, and structures may be unique to each legacy system [42], and the data may have been obtained, entered, and stored differently. Data may need to be merged, which may be an added challenge. The VHA has encountered these problems and has approached the 
challenges presented by its legacy systems, unconsolidated data, and multiple databases by implementing the CDW because attempts to apply common standards across legacy systems were impractical. Essentially, it was more practical and efficient to create a vast, modern data structure and repository than to attempt to modernize or to redesign historic systems.

In addition to its focus on improving data and systems, VHA is increasingly focused on data users. There are valuable, user-focused resources such as the VHA data portal (an online gateway to VHA data information, resources, and training), VIReC (a resource center designated to provide guidance to VHA researchers using data), and VA Informatics and Computing Infrastructure (an environment that provides researchers access to analytical tools and clinical and administrative data sets). User-focused resources such as these facilitate practical access to data, knowledge about and use of available data sources, and project collaboration so that individuals can more efficiently and quickly produce information using VHA data.

Finally, although the VHA has several programs and services to help researchers, the ability to retrieve and use EHR and administrative data may depend on the researcher's technical knowledge and skills (e.g., knowledge of the data source structures, ability to conceptualize what data are available or can be utilized, knowledge of natural language processing or qualitative methodologies) or access to individuals with these skills.

There are several limitations to this study. The small sample size limits the ability to generalize findings to other VHA pain researchers. Because the survey relied on a convenience sample of PRWG members, this sample may not be representative of all those who use VHA EHR and administrative data for pain research. The use of nonstandardized questionnaires and tools as well as selection of data sources based on authors' pain research experience and familiarity with data sources may have affected the findings. It is possible that the survey excluded important and relevant questions and data sources.

\section{CONCLUSIONS}

As researchers continue to use VHA data for pain or other conditions, it is important to understand data sources and methods better so that protocols can be for- mulated to help guide future researchers and studies. Data from this survey provided an opportunity to examine VHA researchers' use of and confidence in the reliability of EHR and administrative data. We assessed respondents perception of barriers to accessing data and the adequacy of the data sources for pain research. In spite of known limitations, VHA pain researchers are capitalizing on the advantages of using EHR and administrative data to conduct pain studies to help ultimately improve healthcare services for Veterans. The VHA National Pain Management Strategy, initiated on November 12, 1998, established pain management as a national priority. Since then (and coincident with greater awareness of prescription opioid-related adverse events), pain research in VHA has increased and findings are increasingly relevant to healthcare providers and policy makers. Thus, the methods used to identify Veterans with pain need to be shared between researchers in the field, and future work comparing, contrasting, and validating these methods against patient-reported outcomes would help us to better understand the accuracy of the data used.

\section{ACKNOWLEDGMENTS}

\section{Author Contributions:}

Study concept and design: J. L. Goulet, C. A. Brandt.

Acquisition of data: J. L. Goulet, R. Czlapinski.

Analysis and interpretation of data: J. L. Goulet, E. A. Abel.

Drafting of manuscript: E. A. Abel, C. A. Brandt, R. Czlapinski, J. L. Goulet.

Critical revision of manuscript for important intellectual content: E. A. Abel, C. A. Brandt, R. Czlapinski, J. L. Goulet.

Obtained funding: J. L. Goulet, C. A. Brandt.

Study supervision: J. L. Goulet.

Financial Disclosures: The authors have declared that no competing interests exist.

Funding/Support: This material was based on work supported by the VA HSR\&D Center of Innovation and Pain Research, Informatics, Multi-morbidities, and Education Center (award CIN 13-047).

Institutional Review: The VA Connecticut Healthcare System Human Subjects Subcommittee approved this investigation.

Participant Follow-up: The authors have no plans to notify the study subjects of the publication of this article because of a lack of contact information due to the anonymous nature of the survey. However, members of the PRWG, from whom this sample was recruited, will be provided with this report.

Disclaimer: The views and opinions expressed in this article reflect those of the authors and do not necessarily reflect of those of the VA. 


\section{REFERENCES}

1. National Center for Veterans Analysis and Statistics. Department of Veterans Affairs statistics at a glance [Internet]. Washington (DC): Department of Veterans Affairs; 2014 [cited 2014 Oct 15]. Available from: http:// www.va.gov/vetdata/docs/Quickfacts/

Homepage_slideshow 06_30_14.pdf

2. Institute of Medicine. Relieving pain in America: A blueprint for transforming prevention, care, education, and research. Washington (DC): National Academies Press; 2011.

3. Tarlov E, Stroupe KT. Advancing veterans' healthcare using electronic data: Lessons learned from researchers in the field. J Rehabil Res Dev. 2010;47(8):vii-xi.

[PMID:21110241] http://dx.doi.org/10.1682/JRRD.2010.08.0148

4. Lisi AJ, Burgo-Black AL, Kawecki T, Brandt CA, Goulet JL. Use of Department of Veterans Affairs administrative data to identify veterans with acute low back pain: A pilot study. Spine (Phila Pa 1976). 2014;39(14):1151-56.

[PMID:24732845]

http://dx.doi.org/10.1097/BRS.0000000000000350

5. Williams BC, Mehr DR, Fries BE. Use of administrative records to describe longitudinal patterns of health services use among veterans. J Am Med Inform Assoc. 1994;1(4): 325-27. [PMID:7719818]

http://dx.doi.org/10.1136/jamia.1994.95236167

6. Cherkin DC, Deyo RA, Volinn E, Loeser JD. Use of the International Classification of Diseases (ICD-9-CM) to identify hospitalizations for mechanical low back problems in administrative databases. Spine (Phila Pa 1976). 1992; 17(7):817-25.

[PMID:1386943]

http://dx.doi.org/10.1097/00007632-199207000-00015

7. Tian TY, Zlateva I, Anderson DR. Using electronic health records data to identify patients with chronic pain in a primary care setting. J Am Med Inform Assoc. 2013;20(e2): e275-80. [PMID:23904323]

http://dx.doi.org/10.1136/amiajnl-2013-001856

8. Finley EP, Bollinger M, Noël PH, Amuan ME, Copeland LA, Pugh JA, Dassori A, Palmer R, Bryan C, Pugh MJ. A national cohort study of the association between the polytrauma clinical triad and suicide-related behavior among US Veterans who served in Iraq and Afghanistan. Am J Public Health. 2015;105(2):380-87. [PMID:25033126] http://dx.doi.org/10.2105/AJPH.2014.301957

9. Frayne SM, Berg E, Holmes TH, Laungani K, Berlowitz DR, Miller DR, Pogach L, Jackson VW, Moos R. Mental illness-related disparities in length of stay: Algorithm choice influences results. J Rehabil Res Dev. 2010;47(8):
709-18. [PMID:21110246]

http://dx.doi.org/10.1682/JRRD.2009.08.0112

10. Holowka DW, Marx BP, Gates MA, Litman HJ, Ranganathan G, Rosen RC, Keane TM. PTSD diagnostic validity in Veterans Affairs electronic records of Iraq and Afghanistan veterans. J Consult Clin Psychol. 2014;82(4):569-79.

[PMID:24731235]

http://dx.doi.org/10.1037/a0036347

11. Owen RR, Thrush CR, Cannon D, Sloan KL, Curran G, Hudson T, Austen M, Ritchie M. Use of electronic medical record data for quality improvement in schizophrenia treatment. J Am Med Inform Assoc. 2004;11(5):351-57.

[PMID:15187073]

http://dx.doi.org/10.1197/jamia.M1498

12. Fultz SL, Skanderson M, Mole LA, Gandhi N, Bryant K, Crystal S, Justice AC. Development and verification of a "virtual" cohort using the National VA Health Information System. Med Care. 2006;44(8 Suppl 2):S25-30.

[PMID:16849965] http://dx.doi.org/10.1097/01.mlr.0000223670.00890.74

13. Justice AC, Dombrowski E, Conigliaro J, Fultz SL, Gibson D, Madenwald T, Goulet J, Simberkoff M, Butt AA, Rimland D, Rodriguez-Barradas MC, Gibert CL, Oursler KA, Brown S, Leaf DA, Goetz MB, Bryant K. Veterans Aging Cohort Study (VACS): Overview and description. Med Care. 2006;44(8 Suppl 2):S13-24. [PMID:16849964] http://dx.doi.org/10.1097/01.mlr.0000223741.02074.66

14. Mattocks KM, Sadler A, Yano EM, Krebs EE, Zephyrin L, Brandt C, Kimerling R, Sandfort T, Dichter ME, Weiss JJ, Allison J, Haskell S. Sexual victimization, health status, and VA healthcare utilization among lesbian and bisexual OEF/OIF veterans. J Gen Intern Med. 2013;28(Suppl 2): S604-8. [PMID:23807072] http://dx.doi.org/10.1007/s11606-013-2357-9

15. Haskell SG, Brandt CA, Krebs EE, Skanderson M, Kerns RD, Goulet JL. Pain among Veterans of Operations Enduring Freedom and Iraqi Freedom: Do women and men differ? Pain Med. 2009;10(7):1167-73. [PMID:19818028] http://dx.doi.org/10.1111/j.1526-4637.2009.00714.x

16. Haskell SG, Ning Y, Krebs E, Goulet J, Mattocks K, Kerns $\mathrm{R}$, Brandt C. Prevalence of painful musculoskeletal conditions in female and male veterans in 7 years after return from deployment in Operation Enduring Freedom/Operation Iraqi Freedom. Clin J Pain. 2012;28(2):163-67.

[PMID:21677563]

http://dx.doi.org/10.1097/AJP.0b013e318223d951

17. Kern EF, Beischel S, Stalnaker R, Aron DC, Kirsh SR, Watts SA. Building a diabetes registry from the Veterans Health Administration's computerized patient record system. J Diabetes Sci Technol. 2008;2(1):7-14.

[PMID:19885172] http://dx.doi.org/10.1177/193229680800200103 
18. Miller DR, Pogach L. Longitudinal approaches to evaluate health care quality and outcomes: The Veterans Health Administration diabetes epidemiology cohorts. J Diabetes Sci Technol. 2008;2(1):24-32. [PMID:19885174] http://dx.doi.org/10.1177/193229680800200105

19. Reker DM, Hamilton BB, Duncan PW, Yeh SC, Rosen A. Stroke: Who's counting what? J Rehabil Res Dev. 2001; 38(2):281-89. [PMID:11392661]

20. Ried LD, Cameon R, Jia H, Findley K, Hinojosa MS, Wang $\mathrm{X}$, Tueth MJ. Identifying veterans with acute strokes with high-specificity ICD-9 algorithm with VA automated records and Medicare claims data: A more complete picture. J Rehabil Res Dev. 2007;44(5):665-73.

[PMID:17943678]

http://dx.doi.org/10.1682/JRRD.2007.02.0033

21. Shi Q, Langer G, Cohen J, Cleeland CS. People in pain: How do they seek relief? J Pain. 2007;8(8):624-36.

[PMID:17586099]

http://dx.doi.org/10.1016/j.jpain.2007.03.006

22. Sinnott PL, Siroka AM, Shane AC, Trafton JA, Wagner TH. Identifying neck and back pain in administrative data: Defining the right cohort. Spine. 2012;37(10):860-74.

[PMID:22127268]

http://dx.doi.org/10.1097/BRS.0b013e3182376508

23. Department of Defense. Defense Manpower Data Center [Internet]. Washington (DC): Department of Defense; 2015 [cited 2015 Feb 10]. Available from: https://www.dmdc.osd.mil/ appj/dwp/index.jsp

24. Goulet JL, Brandt C, Crystal S, Fiellin DA, Gibert C, Gordon AJ, Kerns RD, Maisto S, Justice AC. Agreement between electronic medical record-based and self-administered pain numeric rating scale: Clinical and research implications. Med Care. 2013;51(3):245-50. [PMID:23222528] http://dx.doi.org/10.1097/MLR.0b013e318277f1ad

25. Seal KH, Shi Y, Cohen G, Cohen BE, Maguen S, Krebs EE, Neylan TC. Association of mental health disorders with prescription opioids and high-risk opioid use in US veterans of Iraq and Afghanistan. JAMA. 2012;307(9):940-47. [PMID:22396516] http://dx.doi.org/10.1001/jama.2012.234

26. Department of Veterans Affairs. VHA pain management strategy [Internet]. Washington (DC): Department of Veterans Affairs; 2010 [cited 2014 Oct 7]. Available from: http:// www.va.gov/PAINMANAGEMENT/

VHA Pain Management Strategy.asp

27. Harris PA, Taylor R, Thielke R, Payne J, Gonzalez N, Conde JG. Research electronic data capture (REDCap) - a metadata-driven methodology and workflow process for providing translational research informatics support. J Biomed Inform. 2009;42(2):377-81. [PMID:18929686] http://dx.doi.org/10.1016/j.jbi.2008.08.010
28. Hynes DM. Overview of VA data, information systems, national databases \& research uses [Internet]. Washington (DC): VIReC Database \& Methods Cyberseminar Series, Department of Veterans Affairs; 2014 [cited 2015 Feb 10]. Available from: http://www.hsrd.research.va.gov/for researchers/ cyber_seminars/archives/897-notes.pdf

29. Department of Veterans Affairs. Health Services Research \& Development: Corporate data warehouse [Internet]. Washington (DC): Department of Veterans Affairs; 2014 [cited 2014 Oct 7]. Available from: http://www.hsrd.research.va.gov/ for_researchers/vinci/cdw.cfm

30. Cowper DC, Hynes DM, Kubal JD, Murphy PA. Using administrative databases for outcomes research: Select examples from VA Health Services Research and Development. J Med Syst. 1999;23(3):249-59. [PMID:10554740] http://dx.doi.org/10.1023/A:1020579806511

31. Department of Veterans Affairs. The researcher's guide to VA data: VA Information Resource Center [Internet]. Hines (IL): VIReC; 2014 [cited 2014 Oct 7]. Available from: http://www.virec.research.va.gov/Index.asp

32. VA Information Resource Center. Pharmacy Benefits Management (PBM) Database [Internet]. Washington (DC): Department of Veterans Affairs; 2014 [updated 2014 Jul 8]. Available from: http://vaww.virec.research.va.gov/PBM/ Overview.htm

33. Agency for Healthcare Research and Quality. CAHPS: Surveys and tools to advance patient-centered care [Internet]. Rockville (MD): Agency for Healthcare Research and Quality; 2015 [cited 2015 Feb 10]. Available from: https:// cahps.ahrq.gov/index.html

34. Department of Veterans Affairs. VA Center for Clinical Management Research [Internet]. Washington (DC): Department of Veterans Affairs; 2014 [cited 2014 Oct 7]. Available from: http://www.annarbor.hsrd.research.va.gov/ ANNARBORHSRDRESEARCH/index.asp

35. Department of Veterans Affairs. Health Economics Resource Center [Internet]. Washington (DC): Department of Veterans Affairs; 2014 [cited 2014 Oct 7]. Available from: http:// www.herc.research.va.gov/include/page.asp?id=home

36. Department of Veterans Affairs. PTSD: National Center for PTSD. Evaluation Division Research [Internet]. Washington (DC): Department of Veterans Affairs; 2013 [cited 2014 Oct 7]. Available from: http://www.ptsd.va.gov/ about/major-initiatives/divisions-research/ evaluation_division_research.asp

37. O'Malley KJ, Cook KF, Price MD, Wildes KR, Hurdle JF, Ashton CM. Measuring diagnoses: ICD code accuracy. Health Serv Res. 2005;40(5 Pt 2):1620-39.

[PMID:16178999] http://dx.doi.org/10.1111/j.1475-6773.2005.00444.x

38. Lurie N, Popkin M, Dysken M, Moscovice I, Finch M. Accuracy of diagnoses of schizophrenia in Medicaid 
claims. Hosp Community Psychiatry. 1992;43(1):69-71. [PMID:1544654]

39. Weiskopf NG, Weng C. Methods and dimensions of electronic health record data quality assessment: Enabling reuse for clinical research. J Am Med Inform Assoc. 2013; 20(1):144-51. [PMID:22733976] http://dx.doi.org/10.1136/amiajnl-2011-000681

40. Benin AL, Fenick A, Herrin J, Vitkauskas G, Chen J, Brandt C. How good are the data? Feasible approach to validation of metrics of quality derived from an outpatient electronic health record. Am J Med Qual. 2011;26(6):441-51.

[PMID:21926280] http://dx.doi.org/10.1177/1062860611403136

41. Krebs EE, Lorenz KA, Bair MJ, Damush TM, Wu J, Sutherland JM, Asch SM, Kroenke K. Development and initial validation of the PEG, a three-item scale assessing pain intensity and interference. J Gen Intern Med. 2009; 24(6):733-38. [PMID:19418100] http://dx.doi.org/10.1007/s11606-009-0981-1

42. Fihn SD, Francis J, Clancy C, Nielson C, Nelson K, Rumsfeld J, Cullen T, Bates J, Graham GL. Insights from advanced analytics at the Veterans Health Administration. Health Aff (Millwood). 2014;33(7):1203-11.
[PMID:25006147]

http://dx.doi.org/10.1377/hlthaff.2014.0054

Submitted for publication October 21, 2014. Accepted in revised form July 6, 2015.

This article and any supplementary material should be cited as follows:

Abel EA, Brandt CA, Czlapinski R, Goulet JL. Pain research using Veterans Health Administration electronic and administrative data sources. J Rehabil Res Dev. 2016;53(1):1-12.

http://dx.doi.org/10.1682/JRRD.2014.10.0246

ResearcherID/ORCID: Erica A. Abel, PhD: 0000-00017714-8693; Cynthia A. Brandt, MD, MPH: 0000-00018179-1796; Rebecca Czlapinski, MA: L-9848-2015; Joseph L. Goulet, MS, PhD: 0000-0002-0842-804X

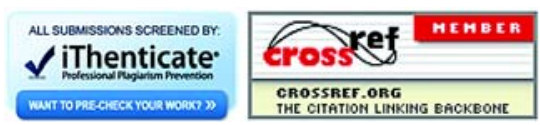



